\title{
FOOD CONSUMPTION DIVERSITY BASED ON LOCAL RESOURCES IN DEALING WITH FOOD SECURITY IN INDONESIA
}

\author{
Hardana Andrean Eka, Haryati Novi, Dewi Heptari Elita \\ Faculty of Agriculture, University of Brawijaya, Malang, Indonesia \\ *E-mail: andrean@ub.ac.id
}

\begin{abstract}
The dependence of community consumption pattern on rice has caused high demand for rice from year to year. These conditions have an impact on the decreasing of local resources diversity. This is because farmers prefer to grow rice. This study aims to explain problems in diversifying food consumption based on local resources and its policy in Indonesia. This is a literature study based on scientific articles related to the issues for 10 years. Result shows that the main problem of food diversification is the imbalance between the pattern of food consumption and the provision of food production and its availability in the community. The Indonesian government has not been sufficiently committed to use the concept of food diversity to replace the consumption patterns of its majority community in rice. Food diversification needs to be developed through the development of various value-added food industries. Large partnerships among stakeholders need to be done by involving all stakeholders, namely local government, research institutions, industry, universities, NGOs and the community.
\end{abstract}

\section{KEY WORDS}

Forcasting, import, crystal sugar, demand sugar.

Food is a basic human need. In accordance with the Food Law (1996), food security is a condition of the fulfillment of food needs for households, not only in sufficient quantities, but also must be safe, quality, nutritious, and diverse; at a price affordable to people's purchasing power. The definition of food as a human right is not only quantitative or sufficient, but also includes qualitative aspects (safe, quality, and nutritious). In the country degan pagsa food expenditure large population is always encountered potential problems of food shortage. The share of food expenditure is used as one indicator of food security. The greater the share of food expenditure, meaning food security is also more vulnerable (Ashari et al, 2012).

Policies on food security in Indonesia are also too often biased towards rice. This resulted in the increasingly thick food pattern of the people to the single staple food, namely rice. This policy on rice also makes it not only a commodity but as a political commodity. The impacts caused by local food are not developed because research investment for non-rice food is also not developed (Hariyadi, 2010).

The development of food security is confronted by the underlying problem where food demand growth is faster than its production growth. Nationally, the rapid growth of food demand both in terms of quantity, quality, and diversity is due to several factors such as the growth of population, industrial growth, and purchasing power of the people, as well as changes in consumer preferences. In addition, the national food production capacity is constrained by competition in land use, extreme climate change, the phenomenon of natural and environmental degradation and the limited support of agricultural infrastructure (Saptana et al., 2013).

Diversification of food consumption became one of the main pillars in reducing food and nutrition problems. In terms of physiological, humans to be active and healthy life requires more than 40 types of nutrients contained in various types of food. Various types of food that exist, there is no single type of food complete nutrition except breast milk (Martianto, 2005). The facts show that diversification of food consumption for the population is an important aspect for the realization of Indonesia's quality human resources. 
Some research studies related to food consumption patterns conducted by the researchers can be concluded that up to now the dependence of people's food consumption on food sources of carbohydrates, especially rice is still very high (more than $60 \%$ ), while on the other hand the role of tubers, animal foods, vegetables and fruits and nuts are still very low. This implies the low score of diversity of food consumption pattern (PPH score) which in the year of 2005 only reached 79,1, far below the ideal score 100 which is expected to be achieved in 2015. In other words, Indonesian food consumption pattern is not yet fulfilled balanced nutrition criteria. This indicates that food diversification programs in Indonesia need to be improved through an accelerated effort (Rachman and Mewa, 2008). These efforts are made by diversifying local food consumption based on local resources.

Food security is developed based on the strength of local resources that will give birth to food self-sufficiency. the condition which in turn will not only give birth to healthy, active, and competitive individuals but also food system which will also become the solid foundation of food security at national level. Therefore, this research will examine the problems in diversification of food consumption based on local resources and its handling in Indonesia.

\section{METHODS OF RESEARCH}

This research was conducted by using literature review study and secondary data collection from various research results that support food consumption diversity based on local resources in dealing with food security in Indonesia as well as related to the implementation of cooperative farming in agribusiness of agricultural commodities. Data collection techniques what can be done is by means of documentation by means of a literature review.

\section{RESULTS AND DISCUSSION}

Problems related to the handling / government policy related to food diversification during this time in Indonesia. Efforts diversification or diversification of food consumption although it has been pioneered since the 60's, but until now still not running as expected. Local food patterns such as abandoned changed to rice patterns and noodle patterns. The average quality of food consumption of Indonesian population is also still low, less diverse, still dominated by carbohydrate source food mainly from the grains. Indonesia's staple food consumption is heavily dependent on rice with an average participation rate of almost 100 percent except for Maluku and Papua (known for sago ecology) ranging from 80 percent (Rachman and Mewa, 2008).

Especially for rice crops which furthermore become a commodity of rice as staple food of society. Keep in mind that efforts to increase production in the future seem to have difficulty yag will be faced in maintaining its availability, this is due to various factors, including: 1). Decreased wetland area, 2) Decrease in soil fertility, 3). Decline in quality and extent of irrigation system services, 4). Lack of adoption of farmers' technology, 5). Ineffective incentive policies, 6). Increasing number of smallholders, 7). The still high yield loss (Simatupang and Maulana, 2006; Agricultural Research Agency, 2005; Food Security Council, 2006).

Research studies conducted by Rachman (2001) indicate a change in the pattern of staple food consumption that tends to lead to a single pattern of rice from the original pattern of rice-tubers, and or rice-tubers. A prominent condition is the suggestion to combine rice with corn, so popular as "rice-corn". There are two meanings of the term: 1) mixture of rice with corn, and 2) replacement of rice consumption at certain times with corn. In subsequent years the government through the Ministry of Agriculture and other departments implement the program, but indeed the results are not as expected (Mewa, 2010).

The main problem of food diversification is the imbalance between the pattern of food consumption and the provision of food production / availability in the community. Production of various types of food can not be produced in all regions and can not be produced any time needed. On the other hand, food consumption is carried out by all residents and every time is 
needed. such conditions of availability and distribution of different types of food in each region are important in relation to efforts to diversify food consumption in addition to access and household purchasing power (Rachman and Mewa, 2008).

Development of diversification of food consumption of the population is inseparable from the level of knowledge about food and nutrition. This is related to the problem that both shortcomings and excess food and nutrients will cause health problems. For low-income people and low access to food, food and nutrition knowledge of the population is needed to increase their understanding of the importance of efforts that lead to the fulfillment of consumption in accordance with the ideal recommendation in terms of quantity and quality (diversification) of food consumption. Meanwhile, for people with high income levels and access to food is relatively good, increased knowledge of food and nutrition of the population is needed to increase their understanding that the balance of consumption and food diversification according to the ideal recommendation in terms of quantity and quality (diversification) of food consumption to avoid More nutritional problems need to be given priority (Rachman and Mewa, 2008).

On the consumer side, studies show that potential factors of local production and community income play an important role in influencing the level of diversity of household food consumption. In low socio-economic societies the problem is not only on the quality of food consumption, but also the unmet energy needs. In high-income communities, generally the level of diversity is relatively good despite the tendency of excess nutrients. This is in line with previous studies (Martianto and Ariani, 2004; Manoewoto and Martianto, 2002) which stated that: a) the dependence of people's food consumption on food sources of carbohydrates, especially rice is still very high, and the role of animal food, vegetables and fruits and nuts -still still very low; b) Food Harvest expectation scores reflecting the diversity of food is still low and tend to fluctuate with the development of national economic situation; c) Besides the level of dependence on rice that is still very high, an increase in the contribution of imported food such as flour and its processed products; d) the consumption of fast food / eating outdoors, especially fast-food managed by multinationals, has increased; e) efforts to increase the value of local food organoleptics (yams, beans, etc.) supported by the development of simple technology for small and medium enterprises proved able to increase local consumer food preferences; and f) the allocation of research funds in agriculture and food is still highly biased on rice, and less directed to other local food (Rachman and Mewa, 2008).

Potential development of local potential as a form of local food diversification (diversification) strategy. The momentum of regional autonomy to build national food selfsufficiency became a form of strategy in diversification (diversification) of local food. This needs to pay attention to the potential, especially regarding the condition, the area and the condition of the environment, and then Indonesia has a great opportunity to realize the independence of food. Local governments need to re-evaluate whether rice is the right staple for the region. Local governments need to seriously explore their local potentials in terms of basic food, which is more in line with their natural environment and cultural environment (Hariyadi, 2010).

The concept of food diversification should be defined as diversification horizontally, vertically and regionally. That is, each region, in accordance with regional autonomy and independence in managing their respective areas, need to seek regional food self-sufficiency in accordance with the potential of each region. The program then needs to be affirmed with the political commitment of the local government that is politically supported also by the central government (Hariyadi, 2010).

Diversification of staple food consumption is not intended to replace the total rice but to change the pattern of food consumption of the community so that people will consume more types of food and better nutrition. Consumed food will be diverse, nutritious and balanced. In Indonesia there are guidelines to measure the diversification of food consumption including staple food known as the Food Pattern of Hope (PPH) (Ariani, 2010).

The pattern of consumption of staple food in Indonesia is shifting from diverse local resource-based patterns to rice and wheat patterns (including derivatives). Consequently, 
rice consumption level is still above $100 \mathrm{~kg} /$ capita / year, on the contrary for local food such as maize is only $2.9 \mathrm{~kg}$ and tubers $12 \mathrm{~kg} /$ capita / year. Diversification of staple food still not in accordance with ideal food pattern as stated in PPH. Consumption of the above recommended grains, on the contrary for the tubers is still smaller than it should be (Ariani, 2010).

The pattern of consumption of Indonesian society still needs to be improved its diversity, both for food staple and for other types of food. Diversification of food also becomes one of the main pillars in realizing food security. Especially when referring to the concept of nutrition that no one type of food complete nutrients in accordance with human needs for healthy living. In terms of physiological, humans to be active and healthy life requires more than 40 types of nutrients contained in various types of food. There is no single type of food complete nutrition except breast milk (Ariani, 2010).

The staple food for society is ideally sourced from local raw materials, so that transport costs can be reduced. Today, Indonesians living in tropical areas where wheat can hardly grow, become the biggest noodle-eating eaters after the PRC. Actually so many other types of tubers other than wheat that can grow well in Indonesia and can be an alternative to food security. People are complacent to consume a lot of residual goods, which are excess products from various countries with low prices that actually turn off the domestic industry itself. But the effort to make local resources a motivation, that Food Diversification program is very possible accepted by the community that is through the 'industry' alternative food that involves the activities of production, distribution, marketing, and promotion.

The strategy (including management of food diversification through industry to have added value). When assessing the diversification of staple food consumption then it is necessary to return to the problem of food decentralization that is local food. Although rice consumption tends to decline but its contribution to total energy is still above 60 percent while new tubers contribute about 3 percent of energy. Various tubers have a broad enough prospect to be developed as a substitution of rice and to be processed into prestigious food. This activity requires the support of process technology development and processing as well as a good marketing strategy to transform the image of inferior food into normal and even superior food (Mewa, 2010).

Efforts to meet consumer demand, one of the most important factors in the success of food diversification program is to implement product development. This product is an effort to create a new product that has properties, among others very practical, available in all sizes, if used there is no rest and easily obtained anywhere. With all the busy life of every member of the household and insufficient time to cook the food, the ready-made and ready-to-eat food is the best choice.

The latest policy, the government set a policy to accelerate the diversification of food consumption based on local resources with two strategies, namely: 1) Internalization of food consumes diversification and Business Development and Local Food Industry. The process of internalization is carried out in two ways: 1) Advocacy, campaigning and socialization of diverse, balanced and safe food consumption at various levels to the apparatus and community, and 2) food consumption education through formal and non-formal education. Meanwhile, the development of local business and food industry is done through: 1) Facilitation to UMKM for the development of fresh food business, raw materials industry, foodstuff processed and ready-to-eat foods that are secure based on local resources and 2) Advocacy, sociation and implementation standard of quality and food safety for food business actors, especially household scale business and UMKM.

One of the important programs in the development of food self-sufficiency is to revitalize the old program of "food diversification". The old program of food diversification has never been seriously and continuously done consistently by the government. Therefore, now is the time to really implement and revitalize the food diversification program. Therefore, there is a strong and clear commitment from the government regarding this diversification program, which in turn will create conducive social environment and react positively to the diversification program (Hariyadi, 2010). 
The government has established a policy to accelerate the diversification of food consumption based on local resources. Learning from the experience of diversification of food consumption so far, the implementation of the policy should be used as a mass movement, not just a government program, so that all levels of society both at the center and in the region must participate and be responsible to make it happen. In addition, there needs to be strong and consistent support from local governments and DPRDs to implement the policy.

In particular, food technology needs to play a role in the development of industrial diversification of food, certainly based on local resources. Therefore, several things are needed: (i) exploration and utilization of potential of superior local materials; (ii) improvement and application of cultivation technology, processing, packaging; and (iii) the application of the concept of food industry. The industry of food diversity needs to be done by creating added value, in such a way that the local food products produced have more value, or at least the same as the staple food products of rice (and wheat) that currently dominate the Indonesian national menu. Creation of this added value is one of the challenges that must be solved by food technology. To that end, research efforts in the field of food science and technology to explore the benefits / functional of local food, and identify and map the preferences and habits of consumers needs to be done intensively (Hariyadi, 2010).

The diversity of natural resources, biodiversity and various types of traditional food owned by the whole region can still be developed to meet the diversification of food consumption. The level of education and development of information technology and public communication strategy can provide an opportunity for the acceleration of the process of raising public awareness towards food that is diverse and nutritiously balanced. Poverty alleviation programs are expected to improve the economic capacity of the people, which in turn also increases food consumption both in terms of both quantity and quality of food consumption (Rachman and Mewa, 2008).

\section{CONCLUSION}

The main problem of food diversification is the imbalance between the pattern of food consumption and the provision of food production / availability in the community. Production of various types of food can not be produced in all regions and can not be produced any time needed. Such conditions of availability and distribution of different types of food in each region are important in relation to efforts to diversify food consumption in addition to access and purchasing power of households. The staple food for society is ideally sourced from local raw materials, so that transport costs can be reduced. Potential development of cultivation berbgai other types of tubers other than wheat that can grow well in Indonesia and can be an alternative to food security. The government has established a policy to accelerate the diversification of food consumption based on local resources. Implementation of the policy should be used as a mass movement, not just a government program. In addition, the management of food diversification through industry to have added value through the use of food technology in the food diversification industry, of course based on local resources

\section{REFERENCES}

1. Agriculture Research and Development Berau. (2005). Sugar Cane in Indonesia. Agriculture Berau. Jakarta.

2. Bernatonyte, D. Burksaitiene, D. \& Rimiene, K. (2013). Trade Specialization Pattern of Lithuania. Economics and Management: 2013. 18 (4).

3. Bernatonyte, D. \& Normantiene, A. (2009). Estimation of Trade Specialization: the Case of the Baltic States. Ekonomika-Engineering Economics (2).

4. Burger, K. Kameo, D. \& Sandee, H. (2001). Clustering of Small Agro-Processing Firms in Indonesia. International Food and Agribusiness Management Review, 2(3/4): 289-299.

5. Caporale, G. M. \& Sova, R. (2015). Trade Flows and Trade Specialisation: The Case of China. Working Paper No. 15-07. 
6. Churmen, Imam .(2001). Save sugar industry in Indonesia. Millenium Publisher. Jakarta.

7. Dachliani, D. (2006). Demand of sugar import on 1980-2003 in Indonesia. (Thesis). Faculty of Economic. Diponegoro University. Semarang.

8. Delroy Anthony Armstrong (2004). The Potential Impact of Trade Policy changes on Caribbean Sugar. B.S., Louisiana State University.

9. Dipl.-Ing. Dieter Bahndorf, Udo Kienle. (2004). World Market of Sugar and Sweeteners. OECD-FAO Agricultural Outlook 2016-2025, OECD Publishing, Paris.

10. Firmansyah, (2008). The Position of Competitiveness and Specialization Trading of Tealndonesia in Facing Globalization.Brawijaya. University. Malang.

11. Gaynor, P.E., and R.C. Kirk Patrick.(1994). Tome Series Modeling and Forecasting in Business and Economics. New York, Mc Graw hill.

12. Haley, Stephen.2013. World Raw Sugar Prices The Influence of Brazilian Costs of Production and World Surplus/ Deficit Measures. United States Department of Agriculture

13. Matsumura, Kanichiro (2010). Demand and Supply Structure for Food in Asia. Sustainability 2011, 3, 363-395; doi: 10.3390/su3020363.

14. McConnell, Michael; Erik Dohlman; Stephen Haley. (2010). World Sugar Price Volatility Intensified by Market and Policy Factors.

15. McCormick, A. J. Watt, D. A., Cramer, M. D.(2009). Supply and demand: sink regulation of sugar accumulation in sugarcane. Journal of Experimental Botany, Vol. 60, No. 2, pp. 357-364.

16. Rumánková, Lenka and Smutka, Luboš. (2013). Global Sugar Market - The Analysis Of Factors Influencing Supply and Demand. Volume LXI. No. 2, pp. 463-471.

17. Sa'diyah, C. (2014). Factors that influence of economic performance for crystal sugar in Indonesia. (Thesis). Faculty of Agriculture. University of Brawijaya. Malang.

18. Sinaga, N. (2006). Model Econometric Aplication. IPB Post Graduate. Bogor.

19. Susila, Wayan.R dan Bonar M. Sinaga. (2005). Analysis of Sugar Industry Policy in Indonesia. Jurnal Agro - Ekonomi Volume 23 No. 1, page 30-53.

20. Xue Xu and Hailong Xia (2014). Analysis and Outlook of China's Sugar Industry Development. Proceedings of Selected Articles of 2013 World Agricultural Outlook. 